\title{
Equity- And Entity-Based Multiples In Emerging Markets: Evidence From The JSE Securities Exchange
}

WS Nel, University of Stellenbosch, South Africa BW Bruwer, University of Stellenbosch, South Africa NJ le Roux, University of Stellenbosch, South Africa

\begin{abstract}
Analysts typically distinguish between equity- and entity-based approaches when employing the free cash flow model to perform equity valuations. However, when multiples are used to perform equity valuations, analysts often neglect to distinguish between equity- and entity-based approaches. In addition, limited empirical evidence exists on the relative valuation performance of equity- and entity-based multiples in developed capital markets and the emerging markets literature is entirely silent in this regard. In this paper the valuation accuracy of equity-based multiples is compared to that of entity-based multiples in valuing the equity of South African companies listed on the JSE Securities Exchange for the period 2001-2010. The research results reveal that equity-based multiples significantly outperform entity-based multiples, indicating a potential increase in valuation accuracy of as much as $15.37 \%$.
\end{abstract}

Keywords: Emerging Markets; Multiples; Equity-based Multiples; Entity-based Multiples; Valuation Accuracy; JSE Securities Exchange

\section{INTRODUCTION AND THEORY}

3

orporate valuation practice in emerging markets, such as South Africa, has attracted considerable international interest (Bruner, Conroy, Estrada, Kritzman \& Li, 2002). There are several reasons for this: Firstly, there seems to be a lack of consistency regarding best practice in the valuation of assets in emerging markets. Secondly, emerging markets differ from developed capital markets in terms of factors such as accounting transparency, liquidity, corruption, volatility and taxation systems, which may affect valuation practices. Thirdly, investment inflows into emerging markets are significant enough that improved valuation practices could affect the welfare of international investors. Lastly, many emerging markets account for large parts of the world population and natural resources, which allows them to grow at real rates of two to three times those of developed markets.

However, very little empirical guidance is available regarding valuation practices in emerging markets. Consequently, Bruner et al. (2002) urged the development of a best practice guide for analysts in emerging markets and emphasised the contribution that academic researchers can make in this regard.

The specific contribution that this research paper aims to make is in the field of relative valuations, otherwise known as multiples. Multiples are used extensively in practice (Minjina, 2008; Roosenboom, 2007; Damodaran, 2006), usually in conjunction with valuation methods such as the discounted cash flow (DCF) approach (Liu, Nissim \& Thomas, 2002b). ${ }^{1}$ However, the DCF approach tends to be based on various assumptions and is rather cumbersome, leading many analysts to revert to multiples. Damodaran (2006) argues that, when performing valuations, most analysts employ multiples or a combination of multiples and comparable companies. Even analysts who are stern supporters of more comprehensive equity valuation methods revert to multiples to test their equity values for plausibility (Bhojraj \& Lee, 2002).

\footnotetext{
${ }^{1} \mathrm{~A}$ complete list of acronyms/abbreviations is available in Annexure A, while key variables are defined in Annexure B.
} 
Multiples are employed to value assets in relation to similar assets in the market (Damodaran, 2002). The traditional multiples approach to equity valuations follows four steps (Damodaran, 2009; Schreiner \& Spremann, 2007): Firstly, the two value relevant measures are identified, i.e. the market price variable and a matching value driver. Secondly, a set of comparable companies is selected. Thirdly, a peer group multiple is calculated based on the selection in step two. Lastly, the peer group multiple is applied to the target company's value driver to determine the value of the company's equity.

The emphasis of this paper lies on step one, i.e. whether to select the market price variable and corresponding value driver on an equity- or entity-basis. Equity-based multiples are based on the market price of a share or the market capitalisation (MCap) of an entity. Entity-based multiples, on the other hand, are based on the market value of invested capital (MVIC), i.e. MCap plus preference share capital plus interest-bearing debt. Equitybased multiples would appear to offer a simpler approach, since MCap does not require a further adjustment for debt, as is the case with entity-based multiples. However, from a theoretical point of view, one would be inclined to argue that entity-based multiples should outperform equity-based multiples due to the fact that they are less affected by different capital structures among comparable companies (Suozzo, Cooper, Sutherland \& Deng, 2001).

Although the majority of the existing literature tends to focus on either equity- or entity-based multiples, a study by Schreiner and Spremann (2007) that focused on both, found empirical evidence in favour of equity-based multiples. Using the median error as a performance measure, Schreiner and Spremann compared the equity- and corresponding entity-based performance of 16 multiples on the United States of America (USA) equity market. They concluded that equity-based multiples performed between 2.74 and $31.99 \%$ more accurate valuations than their entity-based counterparts. ${ }^{2}$

Apart from the contribution by Schreiner and Spremann (2007), the international literature on developed markets offers no support for the superiority of equity-based multiples over entity-based multiples, or vice versa. The emerging market literature is silent in this regard. In fact, the distinction between equity- and entity-based multiples is often neglected by analysts and academics. PricewaterhouseCoopers (PwC, 2010) tested the popularity of various multiples in the South African market by surveying the preferences of the top analysts in practice in South Africa. PwC subsequently presented their findings without effectively distinguishing between equity- and entitybased multiples. For example, the top three multiples presented in the PwC report were Price/Earnings, MVIC/Earnings before interest, tax, depreciation and amortisation (EBITDA) and MVIC/Earnings before interest and tax (EBIT). No explicit distinction was made between the equity- and entity bases of these multiples (PwC, 2010). Similarly, Nel tested the valuation performance of primary valuation methods (Nel, 2009b) and multiples (Nel, 2010 \& 2009a) in the South African market without explicitly distinguishing between equity- and entity-based multiples. The aim of this research paper is to address the lack of empirical evidence in this regard and to add an emerging market perspective to the existing literature.

Valuation logic dictates that analysts should take cognisance of the matching principle when constructing multiples, i.e. the choice of value driver should match the choice of market price variable (Pereiro, 2002). This will ensure a proper distinction between equity- and entity-based multiples. Therefore, when using equity-based multiples, only equity holders' claims should be considered, while entity-based multiples (i.e. where MVIC is used as a market price variable) constitute claims of all fund providers on the entity. In the case of equity-based multiples, the denominator could include various items from the statement of comprehensive income, the statement of financial position and the statement of cash flows. However, equity-based value drivers may not be equally apt for entitybased multiples. Profit after tax, book value of equity and ordinary cash dividend, for example, constitute claims to equity holders in particular and are therefore not appropriate value drivers for entity-based multiples. Similarly, when employing entity-based multiples, the denominator should present a claim to all holders on enterprise cash flow and profit (Suozzo et al., 2001). However, to accommodate the empirical testing of the valuation performance

\footnotetext{
${ }^{2}$ Schreiner and Spremann's initial analysis included the valuation performance of forward and knowledge-related multiples. However, for the purpose of comparison, the valuation performance indicates a potential improvement range of $2.74-31.99 \%$, which is presented after the forward- and knowledge-related multiples were omitted from their initial analysis. Forward multiples were omitted since comparative forward multiples are not readily available on South African databases. Knowledge-related multiples, on the other hand, are nonsensical in the South African context as a result of accounting differences between South African and American Generally Accepted Accounting Principles.
} 
of equity-based multiples compared to their entity-based equivalents, the matching requirement is relaxed from an equity-based perspective. Consequently, the value drivers are selected based on their suitability from an entity-based perspective, which seems to be a biased approach, i.e. the design of the empirical investigation seems to favour entity-based multiples.

A similar tendency may be gleaned from valuation theory, which suggests that entity-based multiples offer several benefits over equity-based value multiples. Firstly, entity-based multiples are more comprehensive than equity-based multiples since they value the business as a whole, whereas equity-based multiples focus only on equity value. Secondly, entity-based multiples are less affected by capital structure differences among entities. Thirdly, the value drivers that are generally associated with entity-based multiples, such as EBITDA, are less susceptible to accounting differences caused by differences in companies' tax structures or depreciation policies, for example. Consequently, entity-based multiples are more comparable between entities than equity-based multiples. Therefore, based on valuation theory, one may be inclined to expect superior valuation performance from entitybased multiples relative to their equity-based equivalents.

The valuation performance of equity- and entity-based multiples may be hindered by two caveats. The equity-based caveat is gleaned from conventional capital structure theory, which states that the level of gearing affects the cost of capital and therefore affects valuations. As the level of gearing increases, the costs of financial distress will eventually also increase, which, in turn, will increase the financial risk and therefore the cost of equity. The optimal level of gearing is where the weighted average cost of capital (WACC) is at its minimum, i.e. where the bowl-shaped WACC curve bottoms out.

On the contrary, the Modigliani and Miller (1958) theory assumes that all investors are rational and operate in a tax-less world, with zero transaction costs, zero costs of financial distress and in the absence of asymmetric information and agency problems. Not surprisingly, capital structure in the Modigliani and Miller environment becomes value-irrelevant, i.e. capital structure has no affect on WACC or equity and entity value. However, if the Modigliani and Miller theory holds, different capital structures between entities could erroneously affect equitybased multiples (Schreiner \& Spremann, 2007). Executives may also be tempted to substitute debt with equity in order to orchestrate higher equity-based multiples (Chadda, McNish \& Rehm, 2004).

In reality, investors do not always behave rationally and they do pay taxes and incur transaction costs. Investors may also encounter debt restructuring, insider trading and a conflict of interest with management. In short, capital structure is value-relevant, i.e. capital structure decisions affect the cost of equity and therefore affect equity and entity value. This fact was later conceded by Modigliani and Miller (1963), after they had indicated that the tax shield of debt does, in fact, affect shareholder value.

The entity-based caveat revolves around the market value of debt. The market price variable (MCap) that is used to create equity-based multiples is readily available in the market. However, since the market value of debt is not readily available in the market, no equivalent market price variable (MVIC) exists in the market for the creation of entity-based multiples. As an alternative, MVIC is calculated by adding preference share capital and the book value of debt to MCap. Although the book value of debt may be a reasonable proxy for the market value of debt, it could generate considerable noise if the interest rate or default risk has changed significantly since its issuance (Koller, Goedhart \& Wessels, 2005). Different companies may also have vastly different debt structures which severely complicates the calculation of an appropriate debt figure. That is, the nature of companies' debt may be very different. For example, companies may have more or less long-term, compared to short-term debt, or more or less convertible, compared to non-convertible debt. Companies may also employ different accounting methods to pension liabilities or share options, for example.

The primary aim of this paper is to establish whether equity- or entity-based multiples perform the most accurate equity valuations. The secondary aim is to quantify the potential improvement in valuation accuracy that equity-based multiples may offer over entity-based multiples, or vice versa. To this end, 20 multiples are constructed from two market price variables, one equity-based and one entity-based; and 10 value drivers. Section 2 presents the data selection, followed by a discussion of the research methodology in section 3 . The empirical results of the research are presented in section 4 . Concluding remarks are offered in the final section. 


\section{DATA SELECTION}

The following variables were extracted from the McGregor BFA database: MCap, Preference share capital, Long-term loans: Interest-bearing, Short-term loans: Interest-bearing, Gross profit (GP), Earnings before interest, tax, depreciation and amortisation (EBITDA), Earnings before interest and tax (EBIT), Total assets (TA), Revenue $(\mathrm{R})$, Cash generated by Operations ( $\mathrm{CgbO})$, Increase/decrease in working capital, Net cash inflow from operating activities (NCIfOA), Net cash inflow from investment activities (NCIfIA), Taxation paid, Fixed assets acquired, Net interest paid/received, Secondary tax on companies, Capital profits/losses on financial assets, Normal taxation included in extraordinary items, Total profit of an extraordinary nature and Sector.

The companies were selected based on three criteria: 1) All multiples are positive, i.e. multiples with negative values were discarded, 2) The companies have at least three years of positive company year multiples, and 3) Each sector ${ }^{3}$ has at least four observations that meet criteria 1) and 2) above. The first condition eliminates unrealistic multiples that cannot be used. The second condition ensures that selected companies have a reasonable history as a going concern and the third ensures that the number of companies within each sector is not unnecessarily small, preventing the situation where there are too few observations to warrant a realistic harmonic mean calculation. The final population of observations represents approximately $71 \%$ of the total number of listed companies on the JSE Securities Exchange (JSE) as at 31 December 2010 and approximately $91 \%$ of the market capitalisation of the companies listed on the JSE at the same date, which serves as a fair representation for the conclusions drawn. The number of observations was different for each multiple, depending on how well the variables satisfied the criteria stipulated above. As a result, the multiples have different population sizes, varying between 2080 and 5292 observations. The total number of observations for all the multiples includes 41582 observations, which covered 26 sectors for the period 2001 to 2010.

The data were used to calculate 20 multiples, 10 equity-based multiples, i.e. multiples where MCap is used as the market price variable, and 10 entity-based multiples, i.e. multiples where MVIC is used as the market price variable. The multiples, i.e. the ratio of the market price variables to the respective value drivers, that were used in the analysis are summarised in Table 1.

There are many potential combinations of market price variables and value drivers that may from part of such an exercise. However, for the purpose of this paper, the focus lies on multiples within each of the four most popular value driver categories, namely earnings, book value, revenue and cash flows (Nel, 2010; PwC, 2010; Nel, 2009a; Liu et al., 2002b; Cheng \& McNamara, 2000).

The value drivers were drawn from the statement of comprehensive income (R, GP, EBITDA and EBIT), the statement of financial position (TA and IC) and from the cash flow statement (CgbO, NCIfOA, NCIfIA and FCFF). Since these value drivers are more appropriate for entity-based multiples, one would be inclined to expect that entity-based multiples would outperform equity-based multiples, i.e. the analysis seems to be biased in favour of entity-based multiples.

\footnotetext{
${ }^{3}$ The McGregor BFA industry classifications are industry, supersector, sector and subsector. The sector classification was used for the purpose of this analysis in order to ensure a sufficient number of companies within each industry classification. Although many companies' industry classifications have changed over the past 10 years, for the purposes of this analysis, companies were allocated to the sectors where they resided as at 31 December 2010.
} 
Table 1

Matrix of multiples

\begin{tabular}{|c|c|c|c|c|c|}
\hline & & \multicolumn{4}{|c|}{ Value drivers } \\
\hline & & Earnings & Book value & Revenue & Cash flow \\
\hline \multirow{4}{*}{ 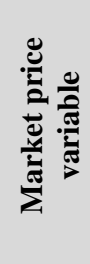 } & \multirow{4}{*}{ 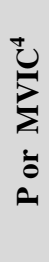 } & GP & TA & $\mathrm{R}$ & $\mathrm{CgbO}$ \\
\hline & & EBITDA & IC & & NCIfOA \\
\hline & & EBIT & & & NCIfIA \\
\hline & & & & & FCFF \\
\hline $\begin{array}{l}\text { P - Ma } \\
\text { MVIC } \\
\text { GP - G } \\
\text { EBITD } \\
\text { EBIT - } \\
\text { TA - T } \\
\text { IC - In } \\
\text { R - Re } \\
\text { CgbO } \\
\text { NCIfO } \\
\text { NCIfIA } \\
\text { FCFF - }\end{array}$ & $\begin{array}{l}\text { lue } \\
\text { ss be } \\
\text { efore }\end{array}$ & $\begin{array}{l}\text { apital } \\
\text { tax, deprec } \\
\text { tax }\end{array}$ & mortisation & & \\
\hline
\end{tabular}

\section{RESEARCH METHODOLOGY}

Analysts typically calculate an industry average multiple and multiply it by a specific entity's value driver, such as EBIT or R, for example, to value an entity's equity (Goedhart, Koller \& Wessels, 2005). This is in line with multiples-based valuation theory, which holds that the actual equity value $\left(V_{i t}^{e}\right)$ of a company $(i)$ at a given point in time $(t)$ is equal to the product of a multiple $\left(\lambda_{t}^{e}\right)$ and a specific value driver $\left(\alpha_{i t}\right)$ at that specific point in time, so that

$V_{i t}^{e}=\lambda_{t}^{e} \cdot \alpha_{i t}$

The primary aim of this paper is to compare the ability of equity-based multiples, based on equation (1), to approximate actual share values with that of entity-based multiples. After the data was extracted from the McGregor BFA database and screened according to the criteria stipulated in section 2, a peer group multiple $\left(\hat{\lambda}_{t}^{e}\right)$ was estimated for each company. The peer group was selected out-of-sample, i.e. by calculating the harmonic mean of all the other remaining companies in the sector. The P/R peer group multiple estimate for company $\mathrm{A}$, for example, in a sector that contains companies $A$ to $E$, would therefore be equal to the harmonic mean of the P/R multiples of companies B to E. The harmonic mean was used to estimate the peer group multiples since it avoids the upward bias of the arithmetic mean and is regarded as a viable and unbiased estimator (Bhojraj \& Lee, 2002; Liu et al., 2002b; Beatty, Riffe \& Thompson, 1999).

The selection of the peer group was based on the McGregor BFA sector-level classification. Sector was selected as the industry classification since previous research concluded that refining the industry classification beyond the sector level added little, if any, value in terms of increased valuation accuracy (Nel, Bruwer \& Le Roux, 2013).

\footnotetext{
${ }^{4}$ As discussed in section 1, the calculation of MVIC requires the inclusion of interest-bearing debt at market value, which is not readily available in the market. Consequently, the book value of interest-bearing debt was used as a proxy.
} 
An equity value prediction $\left(\hat{V}_{i t}^{e}\right)$ is calculated by multiplying each company's estimated peer group multiple $\left(\hat{\lambda}_{t}^{e}\right)$ by the company's actual value driver $\left(\alpha_{i t}\right)$ :

$$
\hat{V}_{i t}^{e}=\hat{\lambda}_{t}^{e} \cdot \alpha_{i t}
$$

Subtracting equation (1) from equation (2) produces (3) for the calculation of the error margin (valuation error):

$$
\hat{V}_{i t}^{e}-V_{i t}^{e}
$$

It is anticipated that (3) will not be independent of value and that the size of the individual company's equity values may distort the size of the valuation errors. Therefore, (3) is expressed proportionally to $V_{i t}^{e}$ to improve the efficacy of the estimated peer group multiple (Beatty et al., 1999). The standardised form of (3), $\varepsilon_{i t}$, is therefore expressed in absolute terms proportionally to $V_{i t}^{e}$, so that

$\varepsilon_{i t}=\left|\frac{\hat{V}_{i t}^{e}-V_{i t}^{e}}{V_{i t}^{e}}\right|$

Note that equations (1) and (2) refer to equity-based multiples in particular. The valuation of equity by means of entity-based multiples will require the use of similar entity-based equations. Equation (1) is adjusted by replacing the equity-based multiple ( $\left.V_{i t}^{e}\right)$ with an entity-based multiple $\left(V_{i t}^{n}\right)$ and debt (d) is deducted from the entity value to obtain the equity value:

$V_{i t}^{e}=\lambda_{t}^{n} \cdot \alpha_{i t}-d$

The equity value prediction $\left(\hat{V}_{i t}^{e}\right)$ is calculated by multiplying each company's estimated peer group multiple $\left(\hat{\lambda}_{t}^{n}\right)$, which is now entity-based, by the company's actual value driver $\left(\alpha_{i t}\right)$, and deducting $\mathrm{d}$ from the entity value prediction $\left(\hat{\lambda}_{t}^{n} \cdot \alpha_{i t}\right)$ :

$$
\hat{V}_{i t}^{e}=\hat{\lambda}_{t}^{n} \cdot \alpha_{i t}-d
$$

As in the case of equity-based multiples, subtracting equation (1) from equation (7) produces (3) for the calculation of $\varepsilon_{i t}$, the error margin:

$$
\hat{V}_{i t}^{e}-V_{i t}^{e}
$$


The absolute valuation errors of each equity- and entity-based multiple are pooled for all the company years. ${ }^{5}$ The use of absolute numbers prevents the netting of positive and negative valuation errors, which may result in artificially low measures of central tendency and dispersion such as the mean, for example. The multiple that produces the most accurate equity valuation will be the multiple with the lowest valuation error, which generally equates to the multiple with the tightest distribution around a central value such as the mean (Pratt, 2005). The seven measures of central tendency and dispersion that will be used to analyse the pooled observations are the mean, median, standard deviation (SD), coefficient of variation (CV), the inter-quartile range (IQR), median absolute deviation (MAD) and the coefficient of MAD (CMAD), which allows comparison with various international studies in this regard (Herrmann \& Richter, 2003; Lie \& Lie, 2002; Liu, Nissim \& Thomas, 2002a; Kim \& Ritter, 1999; Kaplan \& Ruback, 1995).

The performance of the equity- and entity-based multiples is then evaluated by comparing the central tendency and dispersion of their respective valuation errors. This allows for the construction of an optimisation gap, i.e. a gap that indicates the extent to which equity- or entity-based multiples outperform each other. The optimisation gap indicates the potential percentage improvement (IMP) in valuation accuracy that may be secured by employing either an equity-based multiple vis-á-vis an equivalent entity-based multiple, or vice versa. The IMP is calculated as the percentage improvement in valuation accuracy when substituting the least accurate multiple (multiple with the largest $\varepsilon_{\text {it }}$ ) with the most accurate multiple (multiple with the smallest $\varepsilon_{\text {it }}$ ).

\section{EMPIRICAL RESULTS}

The analysis of the equity- and entity-based pools of valuation errors entailed a two-pronged approach. First, the central tendency of the valuation errors in each pool of observations was analysed. This affords one the opportunity to assess the valuation performance of the equity-based multiples in relation to their entity-based equivalents. To this end, the central tendency of the equity-based pool of valuation errors is compared in relation to that of the entity-based pool of valuation errors in order to ascertain which pool contained the smallest cluster of absolute valuation errors. Two measures of central tendency were used to analyse the two pools of valuation errors, namely the mean and the median. Second, the dispersion of each pool of valuation errors around these measures of central tendency was analysed. The variation of the observations in each cluster of valuation errors was compared in order to determine which pool of valuation errors contained the narrowest dispersion of data. Five measures of dispersion were used for this purpose, namely the SD, CV, IQR, MAD, and the CMAD. This affords one the opportunity to assess the relative size of the dispersion of observations in each pool of valuation errors.

\subsection{Descriptive statistics: Central tendency}

Following the application of the estimates $\hat{\lambda}_{t}^{e}$ and $\hat{\lambda}_{t}^{n}$ to the 10 respective value drivers, the valuation performance of the equity- and entity-based pools of $\varepsilon_{\text {it }}$ was analysed. The results concerning the differences in central tendency of the two pools of valuation errors are illustrated in Figures 1 and 2. ${ }^{6}$ The 10 value drivers depicted in these boxplots are ranked according to their relative valuation performance, based on their mean (Figure 1) and median (Figure 2) absolute valuation errors. The value drivers are therefore ranked from those reflecting the highest increase in valuation accuracy, when substituting entity-based multiples with their equity-based counterparts, to those reflecting the lowest increase in valuation accuracy. The percentages in parenthesis indicate the mean- (Figure 1) and median- (Figure 2) based potential improvement in valuation accuracy that may be secured when substituting entity-based multiples with equity-based multiples.

As is evident from Figure 1, all equity-based multiples indicate lower mean valuation errors (depicted as asterisks) than their corresponding entity-based counterparts, i.e. equity-based multiples perform more accurate

\footnotetext{
${ }^{5}$ Functions for the calculation of $\varepsilon_{i t}$ and the statistical analysis thereof, were developed in the R-package (R Development Core Team, 2012), an open source programming language that lends itself to statistical analysis and graphics.

${ }^{6}$ The notches in the boxplots in Figure 1 and Figure 2 indicate approximate 95\% confidence intervals for the respective medians, which allow statistical inference.
} 
valuations than their entity-based counterparts. ${ }^{7}$ However, in order to accommodate the outliers (depicted as bubbles in Figure 1), the scaling of the boxes in Figure 1 were reduced considerably, which, apart from the mean observation, inhibits a more detailed analysis, particularly of the central $50 \%$ of the observations (the boxes). A more detailed analysis of the box area requires that a limited range be set for the boxplots. Subsequently, in Figure 2 the scaling is adjusted to accommodate a more detailed analysis of the boxes. The zoomed illustration in Figure 2 indicates that all the equity-based multiples indicate lower median valuation errors (depicted as horizontal lines in the boxes) than their corresponding entity-based counterparts, i.e. equity-based multiples perform more accurate valuations than their entity-based counterparts. In addition, two important observations are prevalent when comparing Figure 1 and Figure 2. Firstly, all the median valuation errors in Figure 2 are lower than their corresponding mean valuation errors in Figure 1, which is the case for all 10 value drivers. Secondly, the IMPs of the median-based valuation errors are smaller than the corresponding IMPs of the mean-based valuation errors. The reason for both these observations can be traced to the fact that the mean is far more susceptible to outliers than the median, which is also the reason that the ranking of the mean-based valuation errors in Figure 1 is different to the ranking of the median-based valuation errors in Figure 2. The number of outliers is reflected by the bubbles that are visible above the top whiskers in Figure 1. The distance between the bubbles and the top whiskers is a reflection of the magnitude of the outliers. ${ }^{8}$ These outliers naturally affect the measures of central tendency such as the mean, which is one of the main reasons why researchers prefer measures such as the median to the mean (Bhojraj \& Lee, 2002; Liu et al., 2002b; Beatty et al., 1999). Aside from the influence of the outliers, the data do not exhibit a normal distribution pattern. All 20 boxes in Figure 1 are located significantly closer to the bottom whiskers, which indicate that the data is positively skewed.

\footnotetext{
${ }^{7}$ Note, no asterisks are visible for the value driver NCIfIA in Figure 1. This is due to the size of the equity- and entity-based mean valuation errors (14.56 and 16.20, respectively) of the NCIfIA value driver in particular, which can be gleaned from Figure 3. The asterisks for the NCIfIA are therefore situated among the bubbles, i.e. above the top whiskers in Figure 1.

${ }^{8}$ The interval parameters for the top and bottom whiskers in Figure 1 are $[\mathrm{P} 75+1.5$ (P75 - P25); P25 - 1.5 (P75 - P25)]. The observations located outside these interval parameters are flagged as outliers. Note that the outliers occur only above the top whiskers in Figure 1.
} 

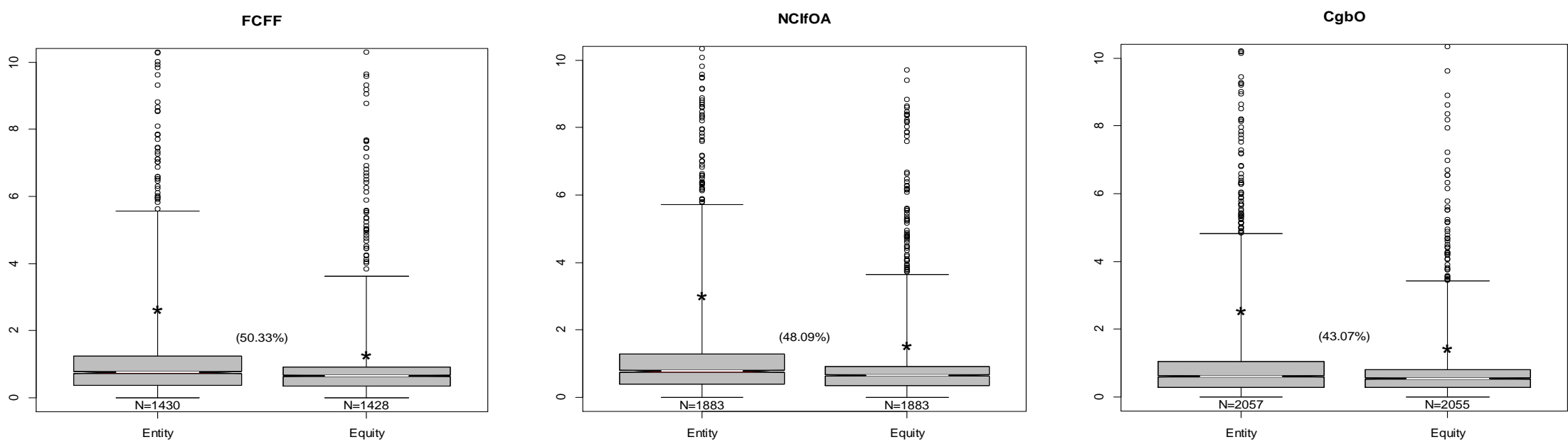

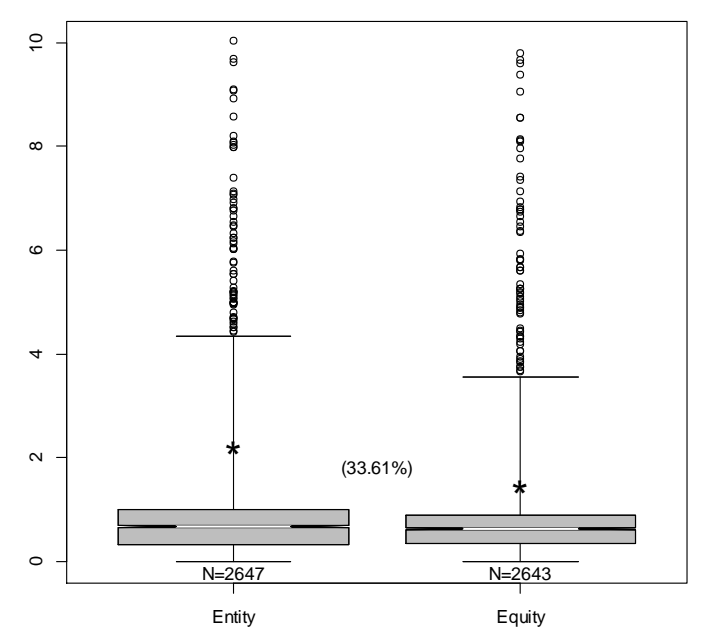

TA

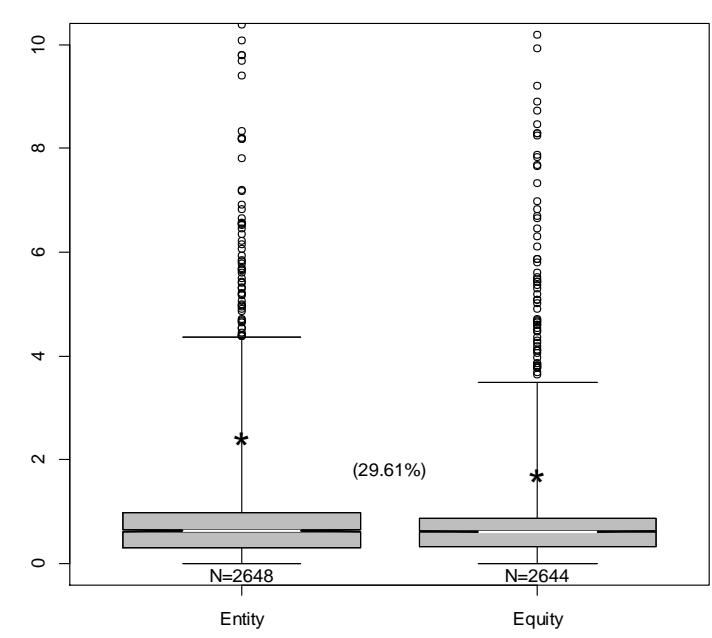

EBITDA

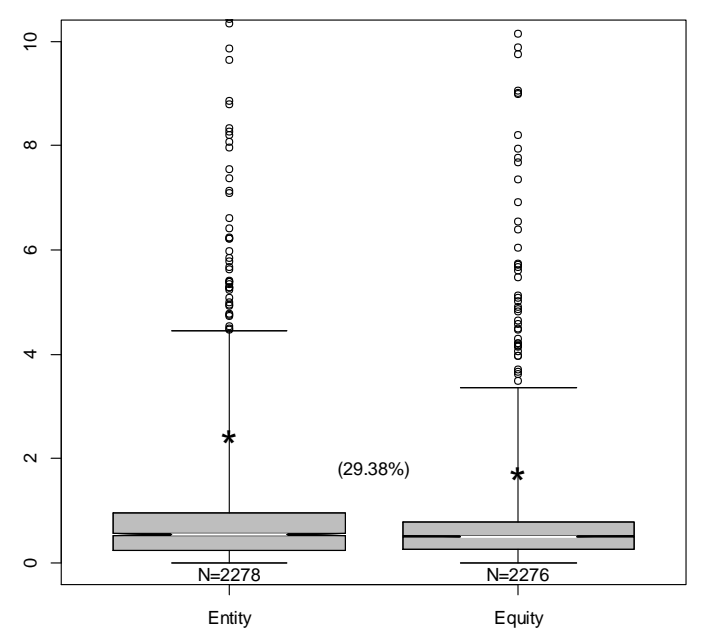

Figure 1: Absolute valuation errors: Entity- versus Equity-based Multiples (Complete range) 
$\mathbf{R}$

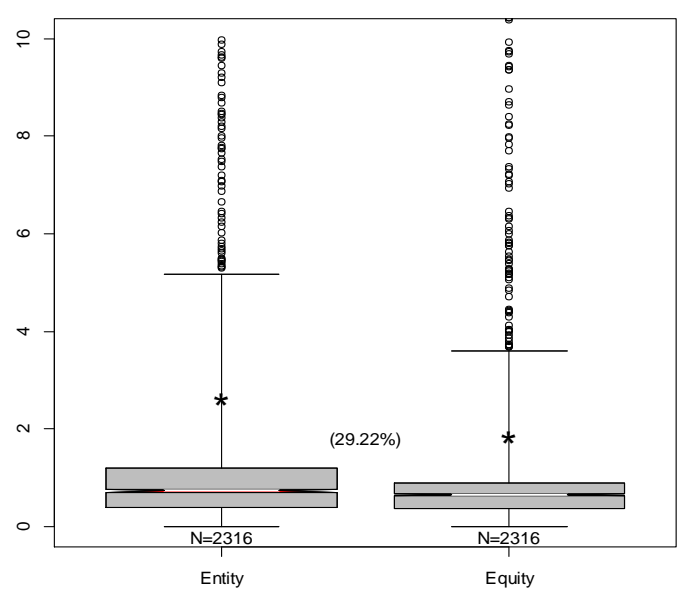

GP

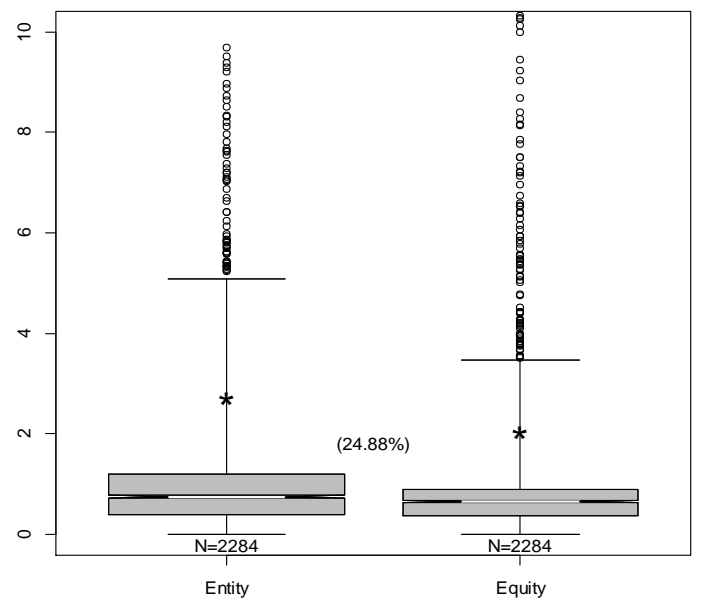

EBIT

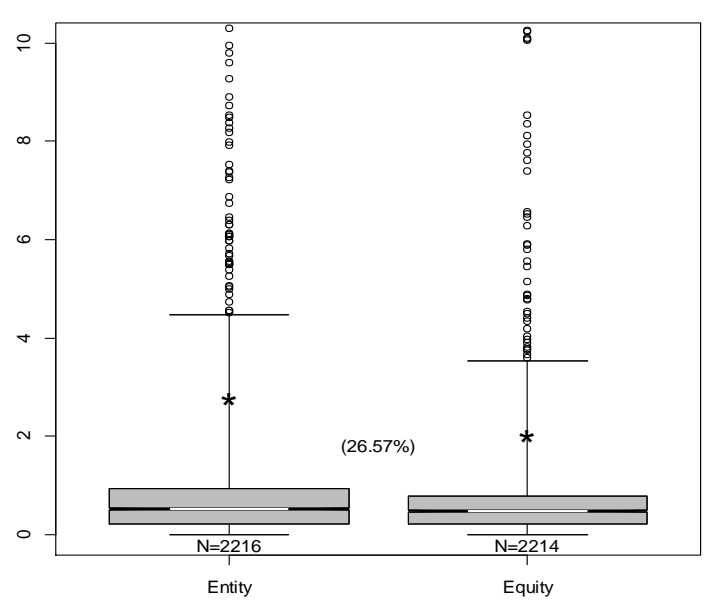

NCIIIA

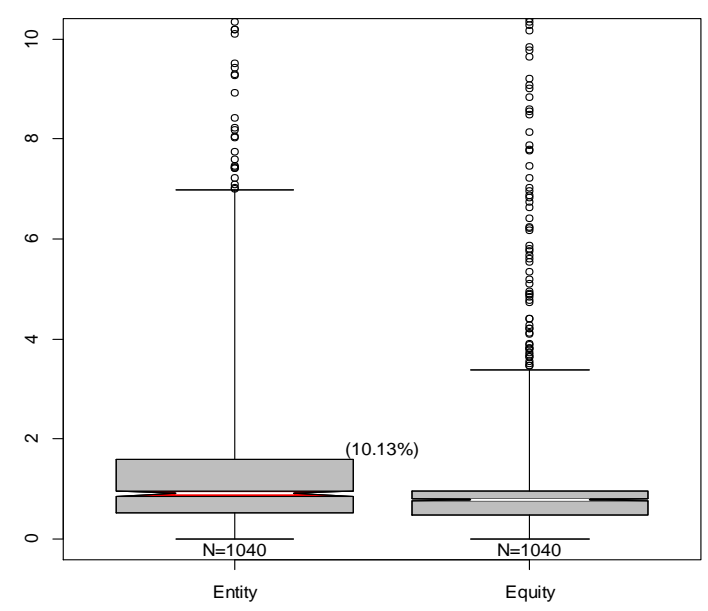

Figure 1...continued 
NCIfOA

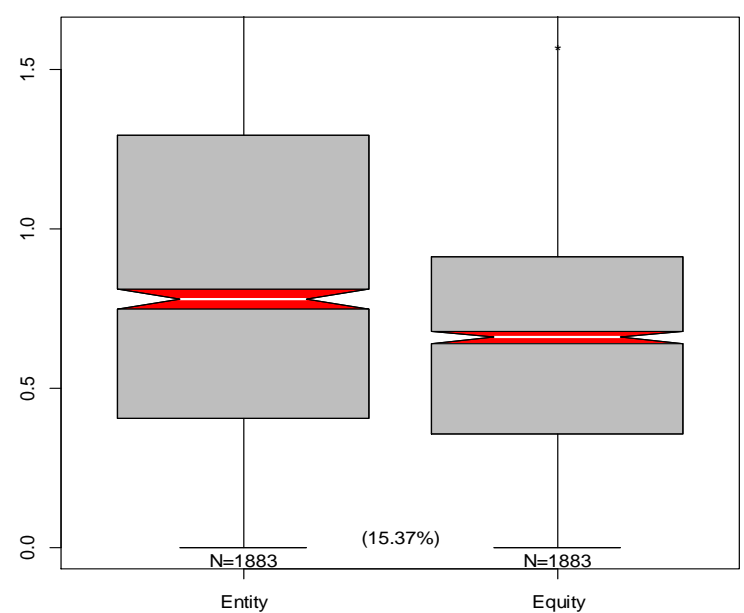

GP

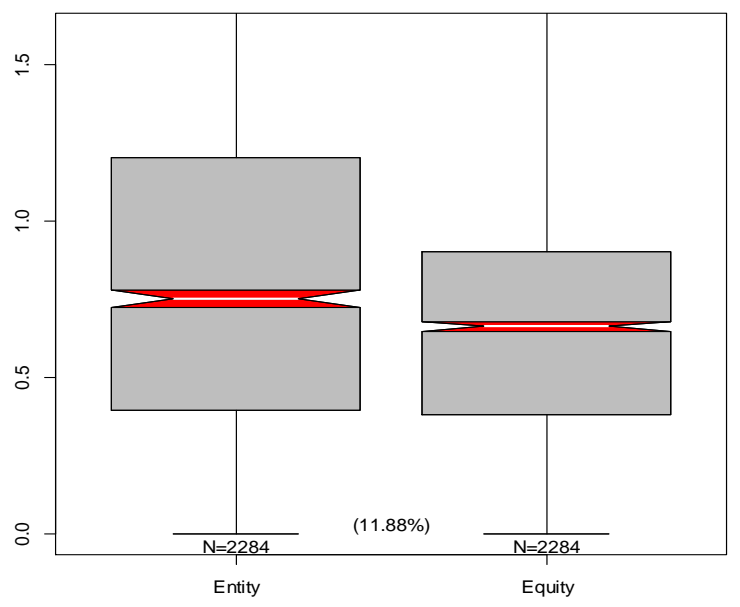

FCFF

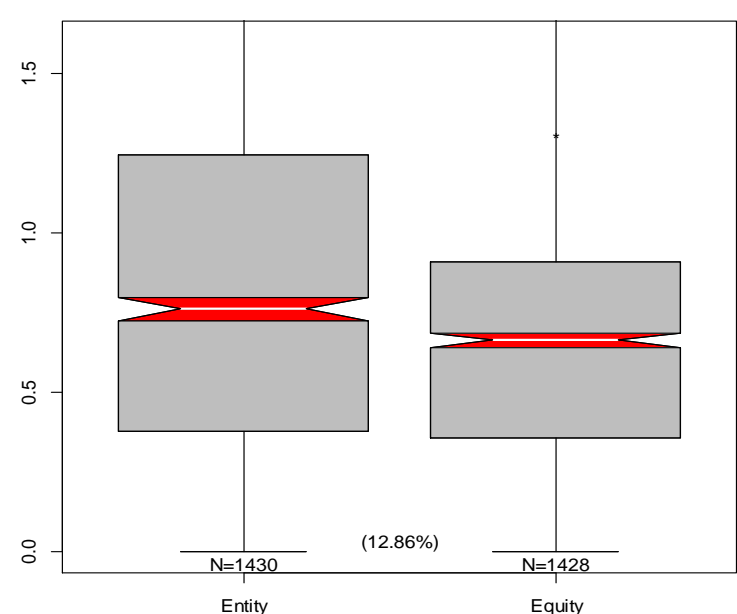

Cgbo

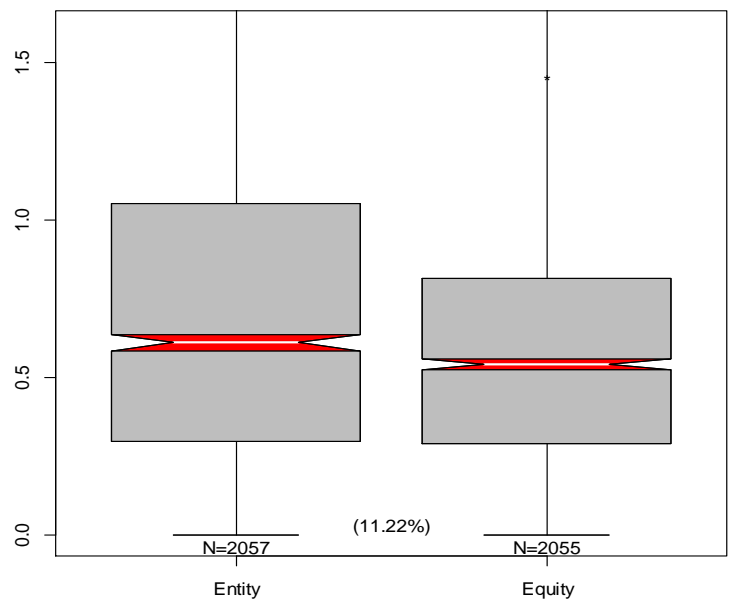

NCIIIA
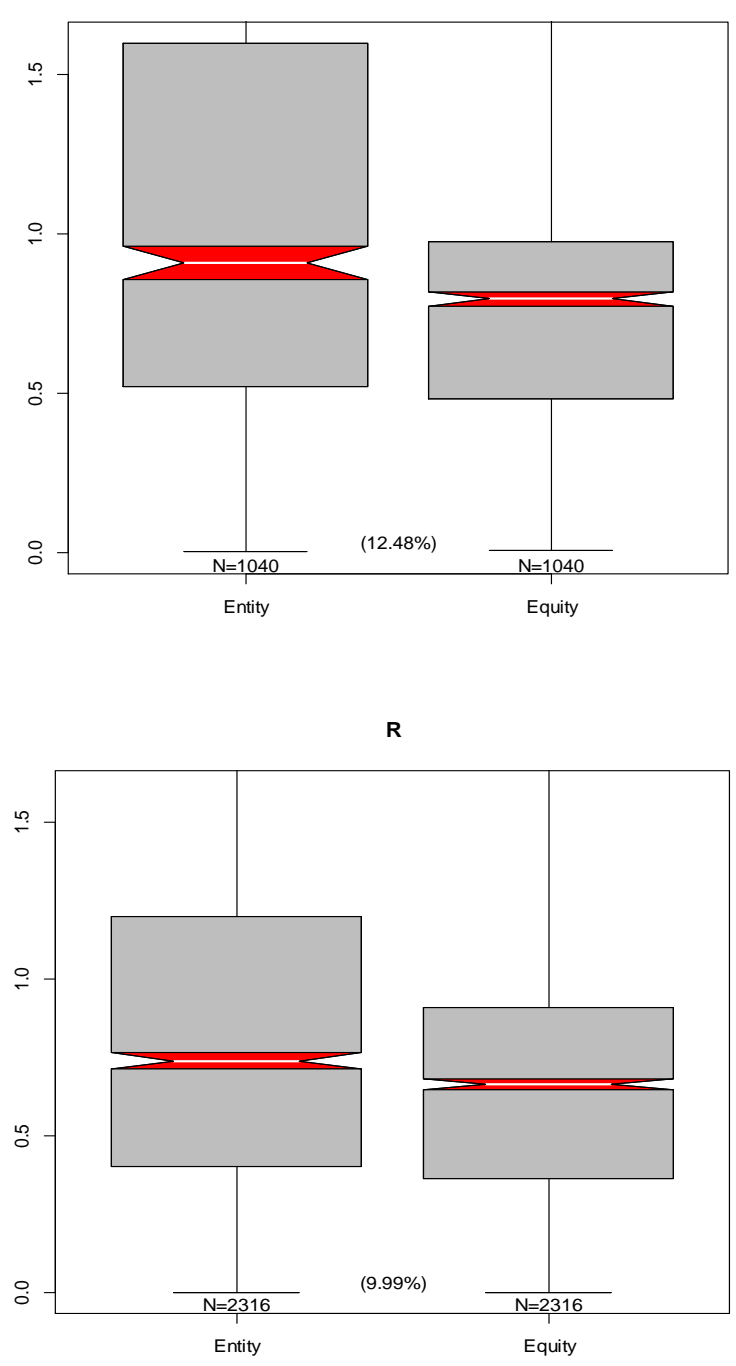

Figure 2: Absolute Valuation Errors: Entity- versus Equity-based Multiples (Limited range focusing on the central 50\% of the observations, i.e. the boxes) 2013 The Clute Institute Copyright by author(s) Creative Commons License CC-BY 
EBIT
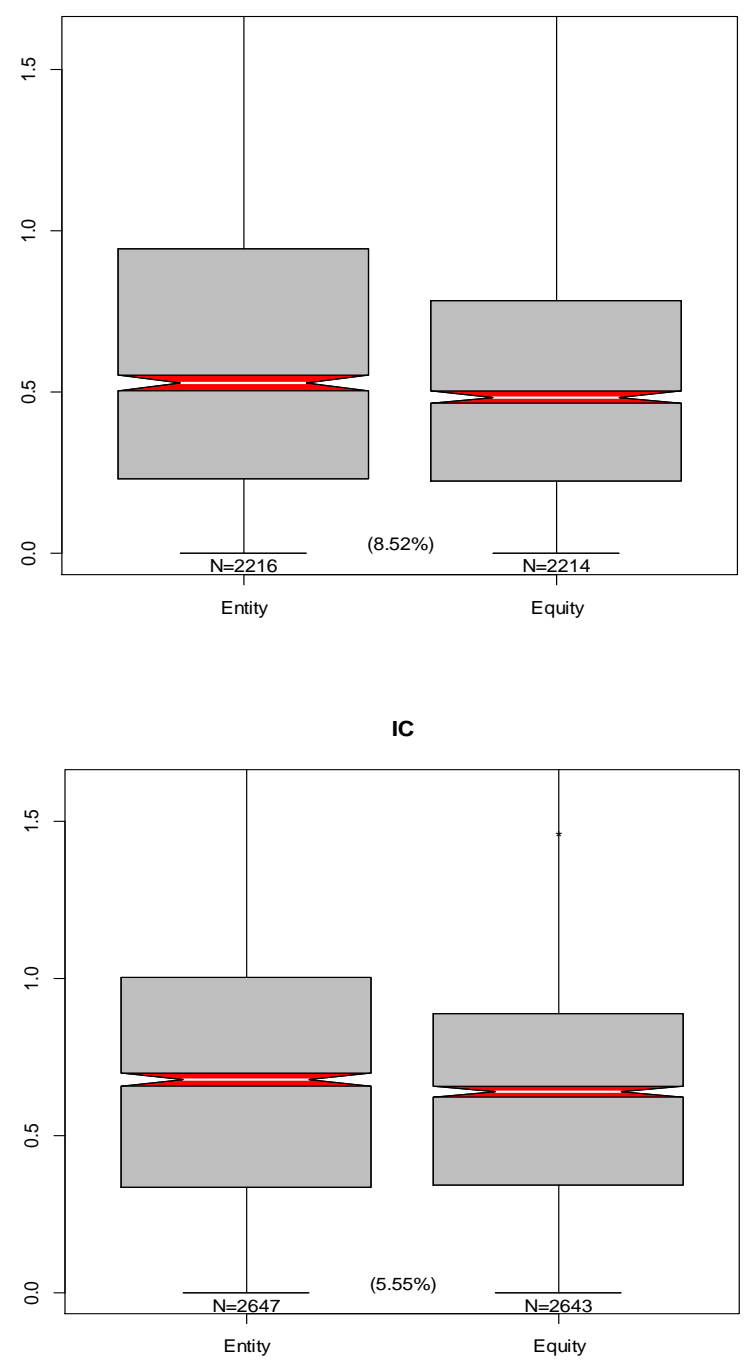

EBITDA

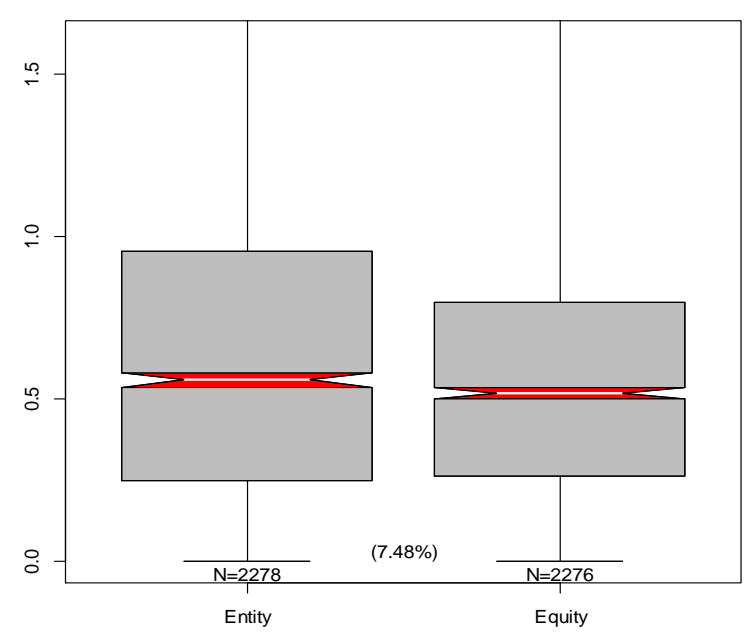

TA

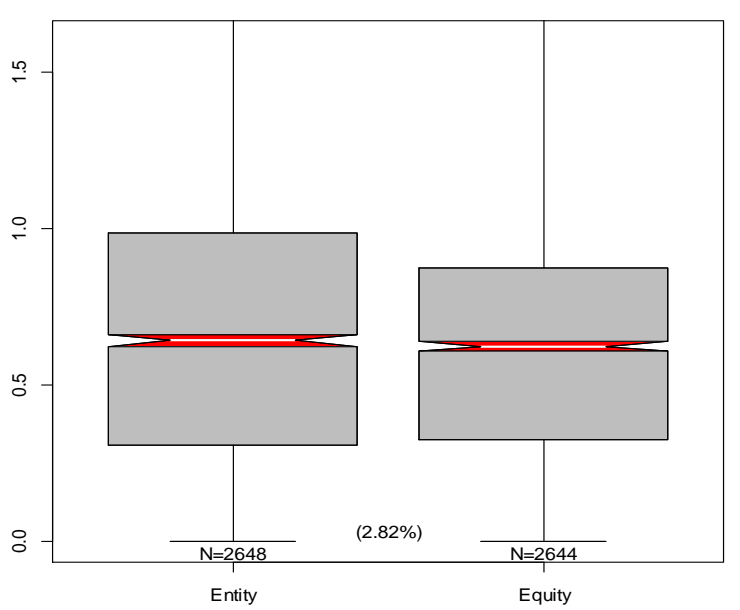

Figure 2...continued 
Although the boxplots in Figure 2 indicate that the lower boundary ( $25^{\text {th }}$ percentile) and the upper boundary $\left(75^{\text {th }}\right.$ percentile) of the boxes decline as entity-based multiples are substituted for equity-based multiples, the decline in the upper boundary is far more significant than that of the lower boundary. All 10 value drivers that were tested demonstrated this tendency. The interquartile ranges also narrow in the boxplots in Figure 2. In addition, the median valuation errors of the upper $50 \%$ of observations and the bottom $50 \%$ of observations decreased when substituting entity-based multiples with equity-based multiples. The latter is in line with the median valuation error of the pooled observations, which also decreased when substituting entity-based multiples with their equity-based counterparts.

The superiority of equity-based multiples is also evident from the radar graphs in Figure 3, which presents a comparative overview of the central tendency-based valuation performance of equivalent equity- and entity-based multiples, i.e. multiples with similar value drivers. Although the scaling of the mean and median is different, this is largely irrelevant for the purpose of the analysis, since the emphasis is on the relative performance of equity- and entity-based multiples. The two measures of central tendency that were employed in the analysis, namely the mean and the median, rendered similar results. The mean and median radar graphs in Figure 3 illustrate that equity-based multiples produce more accurate valuations than their entity-based equivalents. i.e. equity-based multiples have smaller valuation errors than their entity-based equivalents.

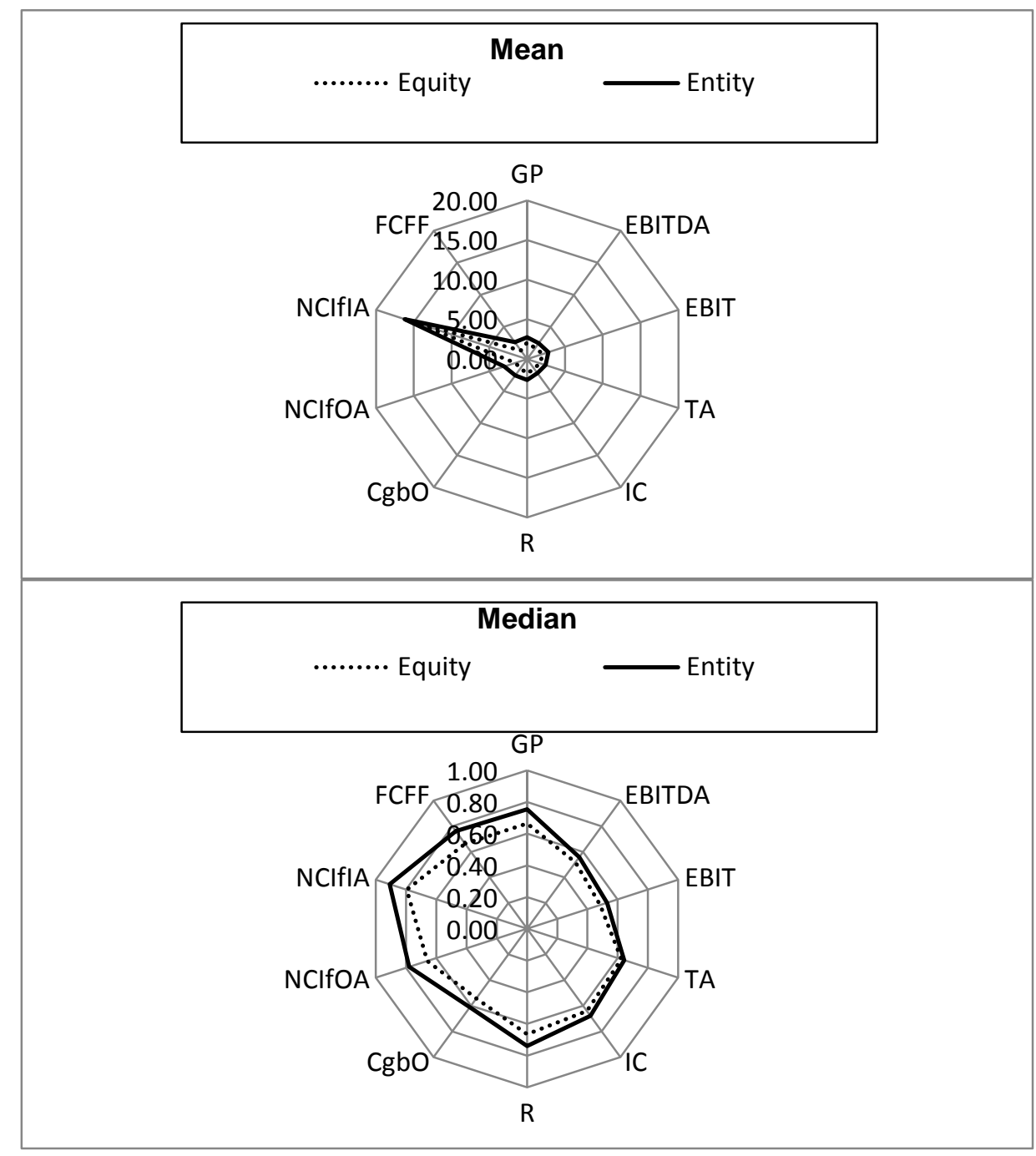

Figure 3: Central tendency of the Absolute Valuation Errors of Equity- and Entity-based Multiples 
The mean indicates a consistent improvement across all the value drivers when substituting entity-based multiples with their equity-based equivalents. The overall mean-based IMP range is 10.13 to 50.33\%, with P/NCIfIA showing the least significant IMP and P/FCFF showing the most significant IMP. However, a comparison of the means, although widely used in statistical analysis, should be approached with the necessary caution. The means were inflated by the outliers, which were particularly prevalent in this study, as can be gleaned from the number of bubbles in Figure 1. The mean's susceptibility to outliers, together with the fact that the data is positively skewed, necessitated the use of a different measure of central tendency such as the median, which is a more robust measure of central tendency.

The median valuation error in Figure 2 indicates a consistent improvement across all the value drivers when substituting entity-based multiples with their equity-based equivalents. The overall median-based IMP range is 2.82 to $15.37 \%$, with P/TA showing the least significant IMP and P/NCIfOA showing the most significant IMP. However, the boxplots in Figure 2 indicate that only $40 \%$ of the notches overlap; and only marginally so, when substituting entity-based multiples with their equity-based counterparts. Consequently, $60 \%$ of the multiples offered statistically significant improvements of the median at the $95 \%$ confidence level. The six multiples that offer improvements of statistical significance are P/NCIfOA, P/FCFF, P/NCIfIA, P/GP, P/CgbO and P/R.

As is evident from the two measures of central tendency, the median offers a more conservative IMP range relative to the mean. As mentioned earlier, the median is a more robust measure of central tendency, since it is less susceptible to the impact of outliers compared to the mean calculation.

The extent to which the mean and the median can be regarded as accurate representatives of the pool of valuation errors will also depend on the variation contained in each pool of valuation errors. While the mean and the median reflect the central tendency of the valuation errors, they fail to describe the dispersion of valuation errors. An equity-based pool of valuation errors, for example, may have a similar mean to that of its entity-based counterpart, while the dispersion in their respective pools of valuation errors may be vastly different. Consequently, it is of equal importance to analyse the dispersion of the opposing pools of valuation errors in order to understand how the data clusters around the mean and the median.

\subsection{Descriptive statistics: Dispersion}

The radar graphs in Figure 4 depict the relative degree of dispersion between the equity- and entity-based multiples, as measured by the SD and the CV. Of particular importance is the dispersion of the valuation errors around the mean, as measured by the $\mathrm{CV}$. The $\mathrm{CV}$ affords one the opportunity to compare the degree of variability between the various equity- and entity-based pools of valuation errors. 


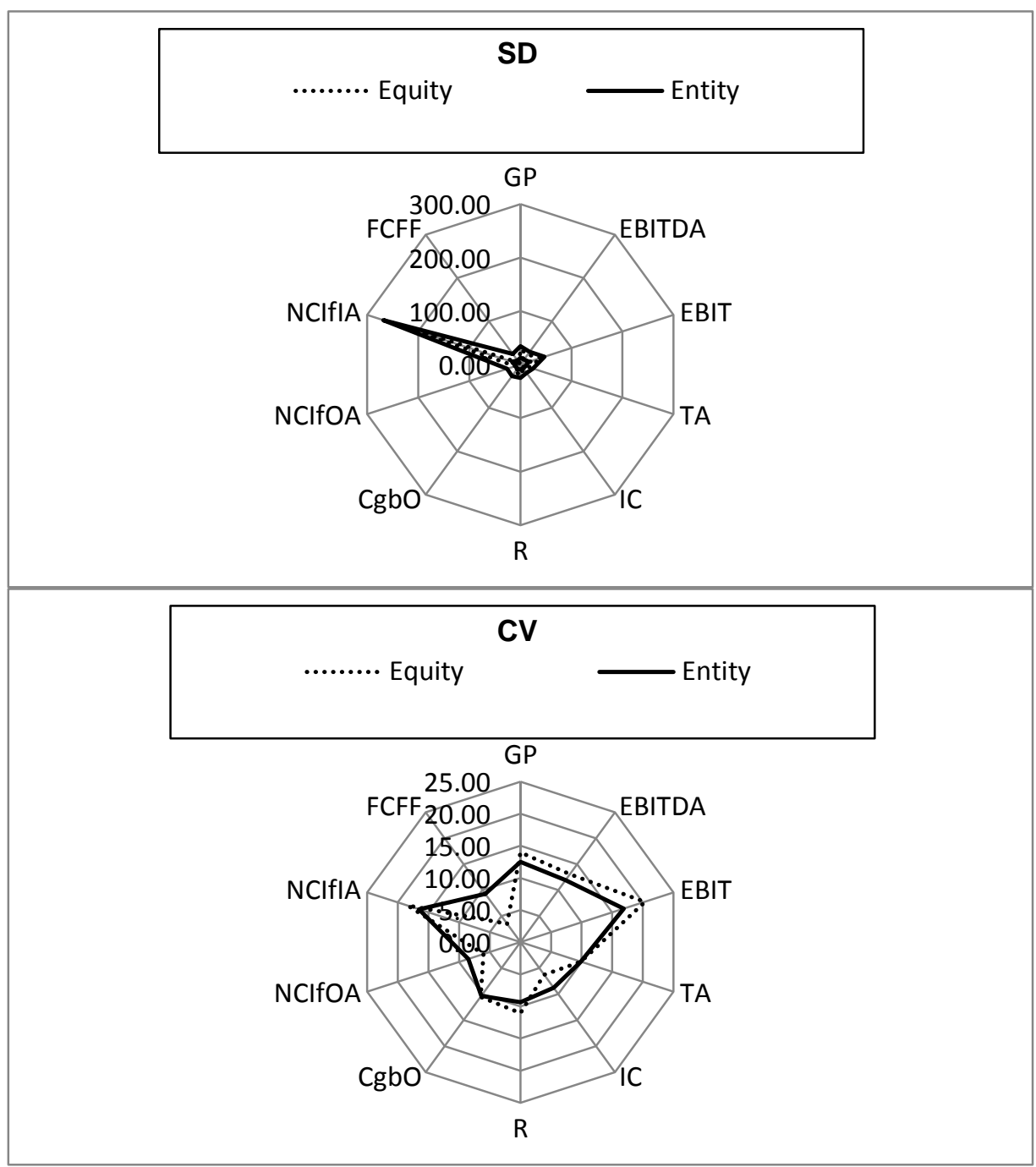

Figure 4: Variability of Absolute Valuation Errors around the Mean: Scale of $\varepsilon_{\text {it }}$ (SD) and Percentage of the Mean (CV)

As is evident from Figure 4, the CV renders inconsistent results, i.e. equity-based multiples do not offer consistently more accurate valuations than their entity-based counterparts, which is reflected in the IMP range of 20.22 to $62.28 \%$. In addition, only $50 \%$ of the value drivers indicate that equity-based multiples exhibit less variability than their entity-based counterparts. The inconsistency of the CV results can be traced to the susceptibility of the SD and the mean to outliers. Consequently, the results of the mean, SD and the CV may be misleading, leading researchers to generally revert to an analysis of the median and the dispersion around it.

The IQR and the MAD are generally regarded as more robust measures of dispersion. The IQR calculation, however, is based on only two values ( $75^{\text {th }}$ and $25^{\text {th }}$ percentiles), while the MAD is based on all observations, which renders it more reliable. In addition to equity-based multiples displaying smaller valuation errors than their entitybased counterparts (as is evident from Figure 3), the IQR and the MAD (as depicted in Figure 5) indicate that equity-based multiples exhibit less variation than their entity-based counterparts. The IQR and MAD display a similar range of IMP across all 10 value drivers. The IQR has an IMP range of 18.12 to 54.02\%, with P/IC showing the least significant IMP and P/NCIfIA showing the most significant IMP, while the MAD reflects an IMP range of 16.77 to 52.94\%, with P/EBIT showing the least significant IMP and P/NCIfIA showing the most significant IMP. 


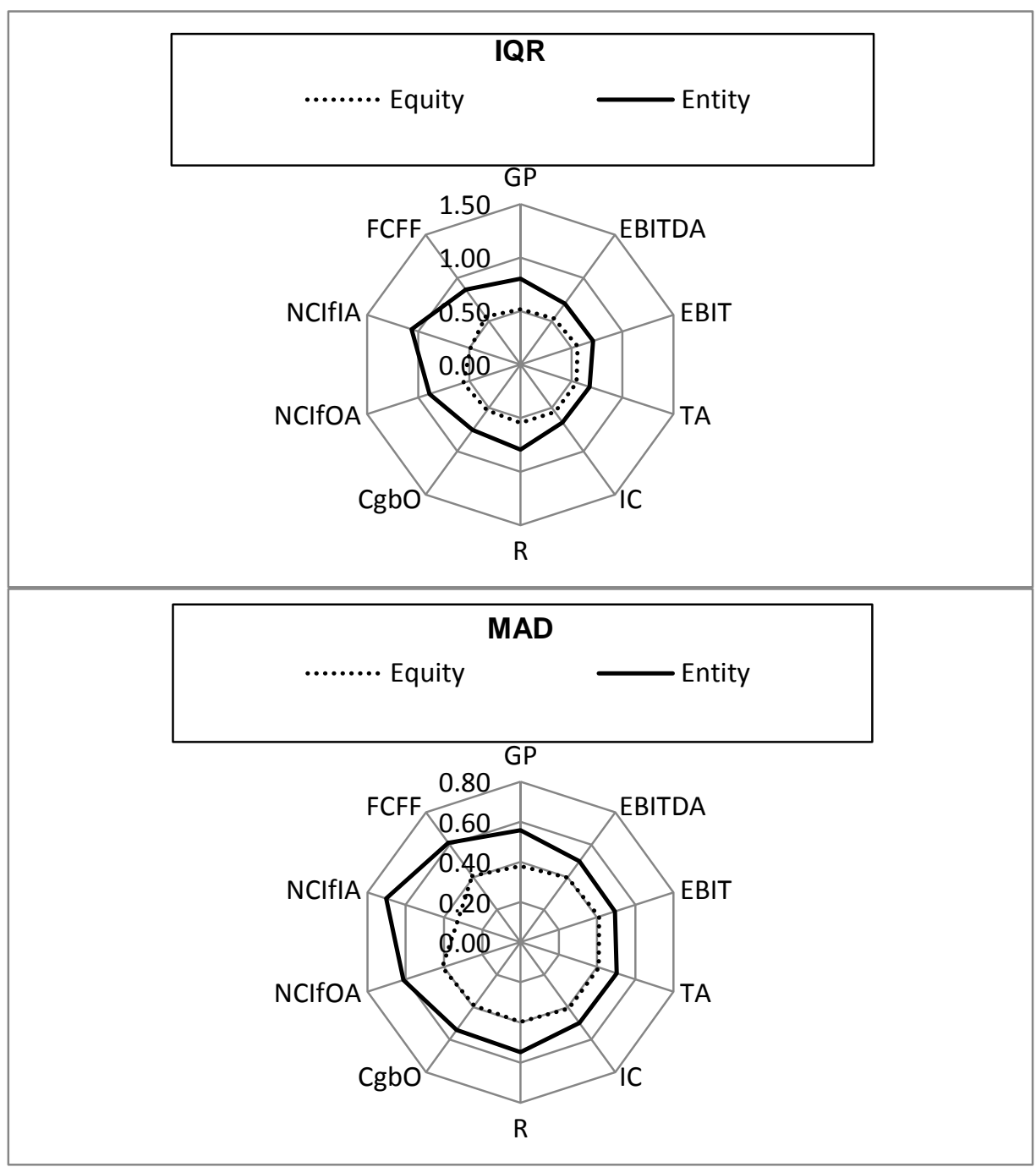

Figure 5: Variability of Absolute Valuation Errors around the Median: Scale of $\varepsilon_{i t}$ (IQR and MAD) and Percentage of the Median (CMAD) 


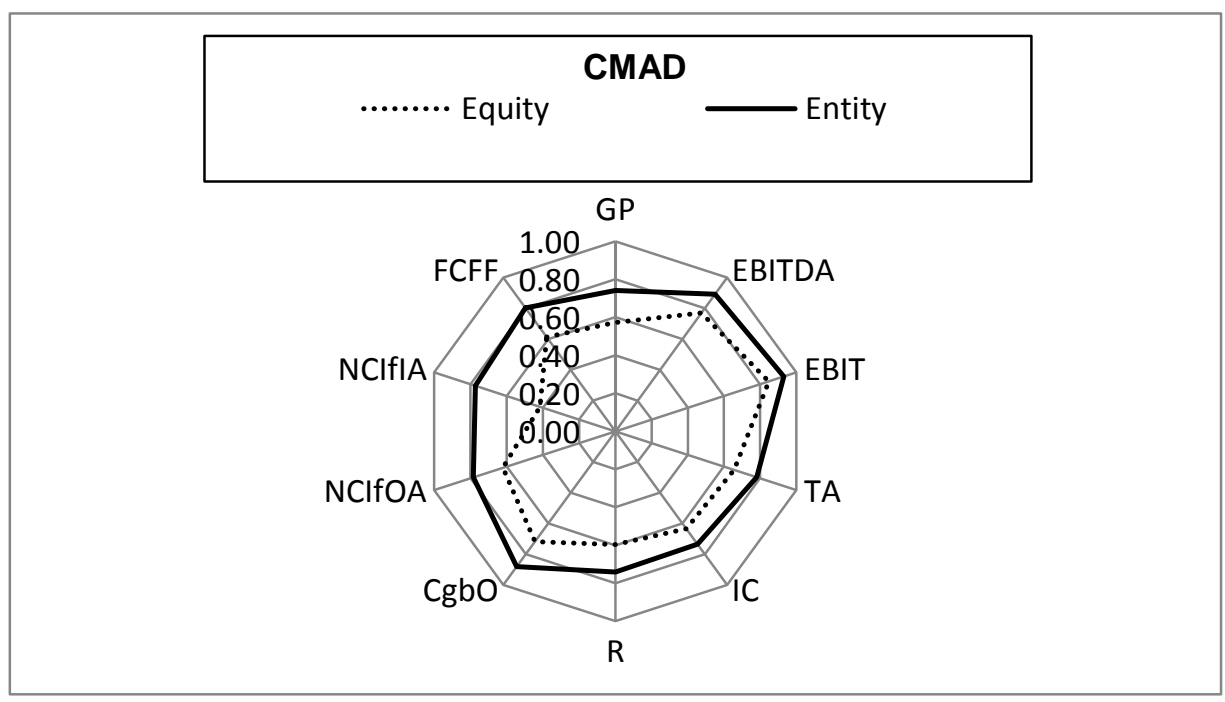

Figure 5...continued

The relative dispersion of the valuation errors around the median is measured by the CMAD, which is a more robust alternative to the $\mathrm{CV}$. Contrary to the $\mathrm{CV}$, which, as illustrated in Figure 4, rendered inconsistent results, the CMAD indicated that, for all the value drivers, equity-based multiples exhibit less variability relative to the respective medians than their entity-based counterparts. The CMAD IMP range was 9.03 to $46.23 \%$, with $\mathrm{P} / \mathrm{EBIT}$ showing the least significant IMP and P/NCIfIA showing the most significant IMP.

Table 2 contains a summary of the relative performance of the equity-based multiples vis-á-vis entity-based multiples, for the construction of an optimisation gap. The optimisation gap indicates the IMP in valuation accuracy that may be secured by substituting the least accurate multiple with the most accurate multiple, i.e. by replacing the largest valuation error with the smallest valuation error. Contrary, to the initial analysis in Figure 1 and Figure 2 , where the emphasis was on the smallest valuation error, the focus in Table 2 is on the highest IMP in valuation accuracy. Consequently, the positive percentages in Table 2 indicate, for each of the two measures of valuation error central tendency and the five measures of valuation error dispersion, to what extent equity-based multiples outperform entity-based multiples. For example, by employing P/GP instead of MVIC/GP, the median-based valuation accuracy of the multiples can be improved by between 2.82 and $15.37 \%$, which is more conservative than the corresponding values found when using the mean. This improvement together with the improvement in the dispersion about the median as found by the MAD or CMAD, suggest that equity-based multiples produce more accurate valuations than entity-based multiples. That is, equity-based multiples consistently offer superior explanatory power of market values vis-á-vis entity-based multiples for six of the seven measures of central tendency and dispersion. Although the consistency of this observation is somewhat obscured by the results of the $\mathrm{CV}$, one needs to take cognisance of the fact that the mean, the standard deviation and the $\mathrm{CV}$ are unduly influenced by outliers, which, as suggested by the bubbles in Figure 1, were quite prevalent in this study. 
Table 2

Optimisation gap: Substituting entity- with equity-based multiples

\begin{tabular}{|c|c|c|c|c|c|c|c|c|}
\hline & \multirow[b]{3}{*}{$\mathbf{N}$} & \multicolumn{7}{|c|}{ IMP } \\
\hline & & Cent & dency & & & Dispersi & & \\
\hline & & Mean & Median & SD & CV & IQR & MAD & CMAD \\
\hline Equity versus Entity & 41582 & $32.49 \%$ & $9.82 \%$ & $33.50 \%$ & $4.64 \%$ & $30.76 \%$ & $28.01 \%$ & $20.37 \%$ \\
\hline $\mathrm{P} / \mathrm{GP}$ versus MVIC/GP & 4568 & $24.88 \%$ & $11.88 \%$ & $15.88 \%$ & $-11.97 \%$ & $35.57 \%$ & $31.90 \%$ & $22.72 \%$ \\
\hline P/EBITDA versus MVIC/EBITDA & 4554 & $29.38 \%$ & $7.48 \%$ & $22.57 \%$ & $-9.63 \%$ & $24.39 \%$ & $20.26 \%$ & $13.81 \%$ \\
\hline P/EBIT versus MVIC/EBIT & 4430 & $26.57 \%$ & $8.52 \%$ & $11.71 \%$ & $-20.22 \%$ & $21.41 \%$ & $16.77 \%$ & $9.03 \%$ \\
\hline P/TA versus MVIC/TA & 5292 & $29.61 \%$ & $2.82 \%$ & $29.94 \%$ & $0.46 \%$ & $18.78 \%$ & $18.44 \%$ & $16.07 \%$ \\
\hline $\mathrm{P} / \mathrm{IC}$ versus MVIC/IC & 5290 & $33.61 \%$ & $5.55 \%$ & $52.17 \%$ & $27.95 \%$ & $18.12 \%$ & $18.20 \%$ & $13.39 \%$ \\
\hline $\mathrm{P} / \mathrm{R}$ versus $\mathrm{MVIC} / \mathrm{R}$ & 4632 & $29.22 \%$ & $9.99 \%$ & $16.17 \%$ & $-18.44 \%$ & $31.44 \%$ & $27.59 \%$ & $19.55 \%$ \\
\hline $\mathrm{P} / \mathrm{CgbO}$ versus $\mathrm{MVIC} / \mathrm{CgbO}$ & 4112 & $43.07 \%$ & $11.22 \%$ & $42.01 \%$ & $-1.87 \%$ & $30.31 \%$ & $27.55 \%$ & $18.40 \%$ \\
\hline P/NCIfOA versus MVIC/NCIfOA & 3766 & $48.09 \%$ & $15.37 \%$ & $63.07 \%$ & $28.85 \%$ & $37.37 \%$ & $33.14 \%$ & $21.00 \%$ \\
\hline P/NCIfIA versus MVIC/NCIfIA & 2080 & $10.13 \%$ & $12.48 \%$ & $0.22 \%$ & $-11.03 \%$ & $54.02 \%$ & $52.94 \%$ & $46.23 \%$ \\
\hline P/FCFF versus MVIC/FCFF & 2858 & $50.33 \%$ & $12.86 \%$ & $81.26 \%$ & $62.28 \%$ & $36.17 \%$ & $33.35 \%$ & $23.51 \%$ \\
\hline Min & & $10.13 \%$ & $2.82 \%$ & $0.22 \%$ & $-20.22 \%$ & $18.12 \%$ & $16.77 \%$ & $9.03 \%$ \\
\hline Max & & $50.33 \%$ & $15.37 \%$ & $81.26 \%$ & $62.28 \%$ & $54.02 \%$ & $52.94 \%$ & $46.23 \%$ \\
\hline
\end{tabular}

IMP - Potential percentage improvement; N - Number of observations; SD - Standard deviation; MAD - Median absolute deviation; IQR - Inter-quartile range; CV - Coefficient of variation; CMAD - Coefficient of MAD; Min - Minimum; Max - Maximum; P - Market price; MVIC - Market value of invested capital; GP - Gross profit; EBITDA Earnings before interest, tax, depreciation and amortisation; EBIT - Earnings before interest and tax; TA - Total assets; IC - Invested capital; R - Revenue; CgbO - Cash generated by operations; NCIfOA - Net cash inflow from operating activities; NCIfIA - Net cash inflow from investment activities; FCFF - Free cash flow to the firm 
The evidence is overwhelmingly stacked in favour of the explanatory power of equity-based multiples vis$a$-vis entity-based multiples, i.e. equity-based multiples explain market values more accurately than their entitybased counterparts. This is confirmed by the fact that the equity-based median valuation errors of all 10 value drivers consistently offered more accurate results than their entity-based counterparts. In addition, an analysis of the dispersion of the valuation errors indicated that equity-based multiples display a smaller degree of variability than their entity-based counterparts. Equity-based multiples consistently outperformed entity-based multiples for the median as a measure of central tendency and for the MAD and the CMAD as measures of dispersion for all 10 value drivers that were tested.

These results gain increased significance if one considers that the multiples that were selected for this study were based on entity-based value drivers. One may therefore be inclined to argue that the design of the study was biased in favour of entity-based multiples. Similarly, valuation theory suggests that entity-based multiples offer various benefits over equity-based multiples, which also favours entity-based multiples. However, despite the bias, equity-based multiples produced more accurate valuations than their entity-based counterparts.

The reason offered by the literature for the superior valuation performance of equity-based multiples is that noise, which is caused when the book value of debt is used as a proxy for the market value of debt, in the estimation of the entity value distorts the accuracy of entity-based multiples (Schreiner \& Spremann, 2007; Koller, Goedhart \& Wessels, 2005). The empirical evidence in this study suggests that the noise is considerable, especially if one considers that valuation theory and the design of this study were biased in favour of entity-based multiples.

\section{CONCLUSION}

The primary focus of this paper was to investigate whether equity- or entity-based multiples perform the most accurate equity valuations. Data was extracted and screened from the McGregor BFA database and subsequently used to calculate two pools of valuation errors, one equity-based and one entity-based. The equity- and entity-based valuation errors were compared in an attempt to establish which multiples produced the most accurate equity valuations. The initial statistical analysis included two measures of central tendency, namely the mean and the median, and five measures of dispersions, namely the SD, CV, IQR, MAD and the CMAD. The statistical analysis of the data revealed that the median was the most appropriate measure for judging the central tendency of the two opposing pools of valuation errors, with the MAD and CMAD as the most appropriate measures of dispersion.

Despite valuation theory favouring entity-based multiples and the bias of the design of the study in favour of entity-based multiples, equity-based multiples consistently produced more accurate valuations in terms of size and spread of valuation errors, than their entity-based counterparts. The superiority of equity-based multiples was confirmed by all the selected multiples. Therefore the research results support the notion that equity-based multiples explain market values better than entity-based multiples, which is in line with empirical evidence from developed capital markets. This is confirmed by the fact that the median valuation errors of all 10 value drivers indicated that equity-based multiples offered consistently more accurate valuations than their entity-based counterparts. In addition, an analysis of the dispersion of the valuation errors indicated that equity-based multiples display a smaller degree of variability than their entity-based counterparts. Equity-based multiples outperformed entity-based multiples for both measures of dispersion, namely the MAD and the CMAD.

The secondary aim was to quantify the potential improvement in valuation accuracy that equity-based multiples may offer over entity-based multiples, or vice versa. By pitting the valuation performance of equity-based multiples against that of entity-based multiples, it is evident that the substitution of an entity-based multiple with its corresponding equity-based counterpart improves the overall accuracy of the individual valuations by between 2.82 and $15.37 \%$, based on the median valuation error, which is a conservative estimate. One should take cognisance of the fact that the study, in particular the selection of value drivers used, was designed from an entity perspective, which may have suppressed the magnitude of the results. From a dispersion perspective, the improvement ranges in valuation accuracy based on the MAD and the CMAD were 16.77 to $52.94 \%$ and 9.03 to $46.23 \%$, respectively. 
The results therefore confirm the superiority of equity-based multiples vis-á-vis entity-based multiples. Why do equity-based multiples outperform entity-based multiples? The only plausible explanation for the suboptimal performance of entity-based multiples is that noise, which is caused when the book value of debt is used as a proxy for the market value of debt, in the estimation of the entity value distorts the accuracy of entity-based multiples. Based on the empirical evidence contained in this study, one must deduce that the noise is considerable, especially if one considers that valuation theory and the design of this study were biased in favour of entity-based multiples.

What are the practical implications of these results? Analysts may be inclined to prefer equity- or entitybased multiples depending on their specific circumstances and objectives. However, the evidence suggests that equity-based multiples are superior to entity-based multiples and should therefore constitute best practice per se. Although, in practice, certain analysts may have a preference for entity-based multiples, this practice contradicts empirical evidence, which strongly suggests that equity-based multiples produce more accurate valuations than their entity-based counterparts.

\section{AUTHOR INFORMATION}

Mr Soon Nel lectures Finance at the University of Stellenbosch in South Africa. He is a qualified chartered accountant and holds a Master of Commerce degree in Economics and a Higher Diploma in Education. Soon's principal research interests are equity valuations, investment appraisals and mergers and acquisitions. He is currently registered for his PhD in Finance. E-mail: snel@sun.ac.za (Corresponding author)

Prof Wilna Bruwer lectures Finance at the University of Stellenbosch in South Africa. She is a qualified chartered accountant and holds an MBA degree and a $\mathrm{PhD}$ in Finance. Her primary research interests include failure prediction, overtrading and cash flow. E-mail: bws1@ sun.ac.za

Prof Niel le Roux lectures Statistics at the University of Stellenbosch in South Africa. He holds various Master of Science degrees, namely in Experimental Psychology, Mathematical Statistics and Geography. Niel also holds a $\mathrm{PhD}$ in Mathematical Statistics. His main research interests include multivariate statistical analysis, multidimensional scaling and graphical representation of multivariate data. E-mail: njlr@sun.ac.za

\section{REFERENCES}

1. Beatty, R.P., Riffe, S.M. \& Thompson, R. (1999). The method of comparables and tax court valuations of private companies - An empirical investigation. Accounting Horizons, 13(3): 177-199.

2. Bhojraj, S. \& Lee, M.C. (2002). Who is my peer? A valuation-based approach to the selection of comparable companies. Journal of Accounting Research, 40(2): 407-439.

3. Bruner, F., Conroy, R.M., Estrada, J., Kritzman, M. \& Li, W. (2002). Introduction to valuation in emerging markets. Emerging Markets Review, 3(4): 300-324.

4. Chadda, N., McNish, R.S. \& Rehm, W. (2004). All P/Es are not created equal. McKinsey on Finance: Perspectives on Corporate Finance and Strategy, Spring: 11-15.

5. Cheng, C.S.A. \& McNamara, R. (2000). The valuation accuracy of the price-earnings and price-book benchmark valuation methods. Review of Quantitative Finance and Accounting, 15(4): 349-370.

6. Damodaran, A. (2002). Investment valuation: Tools and techniques for determining the value of any asset. $2^{\text {nd }}$ edition. New York: John Wiley \& Sons, Inc.

7. Damodaran, A. (2006). Valuation approaches and metrics: A survey of the theory and evidence. $2^{\text {nd }}$ edition. Hanover: Now Publishers, Inc.

8. Damodaran, A. (2009). The dark side of valuations. $2^{\text {nd }}$ edition. New Jersey: Pearson Education, Inc.

9. Goedhart, M., Koller, T. \& Wessels, D. (2005). The right role for multiples in valuation. McKinsey on Finance, 15: 7-11.

10. Herrmann, V. \& Richter, F. (2003). Pricing with performance-controlled multiples. Schmalenbach Business Review, 55(3): 194-219.

11. Kaplan, S.N. \& Ruback, R.S. (1995). The valuation of cash flow forecasts: An empirical analysis. Journal of Finance, 50(4): 1059-1093. 
12. Kim, M. \& Ritter, R. (1999). Valuing IPOs. Journal of Financial Economics, 53(3): 409-437.

13. Koller, T., Goedhart, M. \& Wessels, D. (2005). Valuation: Measuring and Managing the Value of Companies. 4th edition. Hoboken, NJ: Wiley.

14. Lie, E. \& Lie, H. (2002). Multiples used to estimate corporate value. Financial Analysts Journal, 58(2): 4454.

15. Liu, J., Nissim, D. \& Thomas, J. (2002a). Equity valuation using multiples. Journal of Accounting Research, 40(1): 135-172.

16. Liu, J., Nissim, D. \& Thomas, J. (2002b). International equity valuation using multiples. Working paper. Los Angeles: University of California at Los Angeles (Anderson Graduate School of Management).

17. Minjina, D.I. (2008). Multiples and their use for equity valuation on European capital markets. Theoretical and Applied Economics, 11(11): 22-28.

18. Modigliani, F. \& Miller, M.H. (1958). The cost of capital, corporation finance, and the theory of investment. American Economic Review, 48(3): 261-297.

19. Modigliani, F. \& Miller, M.H. (1963). Corporate income taxes and the cost of capital: A correction. American Economic Review, 53(3): 433-443.

20. Nel, W.S. (2009a). The use of multiples in the South African equity market: Is the popularity of the price earnings ratio justifiable from a sector perspective? Meditari Accountancy Research, 17(2): 101-115.

21. Nel, W.S. (2009b). Methods of choice in the valuation of ordinary shareholders' equity. Meditari Accountancy Research, 17(2): 117-135.

22. Nel, W.S. (2010). A South African perspective on the multiples of choice in the valuation of ordinary shareholders' equity: From theory to practice. African Journal of Business Management, 4(6): 930-941.

23. Nel, W.S., Bruwer, B.W. \& Le Roux, N.J. (2013). The impact of industry classification on the valuation accuracy of multiples in the South African capital market. International Business and Economics Research Journal, 12(1): 79-102.

24. Pereiro, L.E. (2002). Valuation of companies in emerging markets: A practical approach. $1^{\text {st }}$ edition. New York: John Wiley \& Sons, Inc.

25. Pratt, S.P. (2005). How to use transactional databases for M\&A. Business Valuation Resources, Portland: Pacific Services, Inc.

26. PricewaterhouseCoopers (PwC) (2010). Valuation Methodology Survey. [online] Available from http://www.pwc.co.za/en/assets/pdf/pwc-valuation-methodology-survey-2010.pdf (Accessed on 14 August 2012).

27. R Development Core Team (2012). R: A language and environment for Statistical computing. R Foundation for Statistical Computing, Vienna, Austria. ISBN 3-900051-07-0, URL http://www.Rproject.org/

28. Roosenboom, P. (2007). How do underwriters value initial public offerings? An empirical analysis of the French IPO market. Contemporary Accounting Research, 24(4): 1217-1243.

29. Schreiner, A. \& Spremann, K. (2007). Multiples and their valuation accuracy in European equity markets. Working paper. Frankfurt: University of Saint Gallen.

30. Suozzo, P., Cooper, S., Sutherland G. \& Deng, Z. (2001). Valuation multiples: A primer. Global equity research report, Warburg: UBS Investment Bank. 


\section{APPENDIX A: ACRONYMS}

\begin{tabular}{|c|c|}
\hline Acronym/Abbreviation & Description \\
\hline BFA & Bureau of Financial Analysis \\
\hline BVE & Book value of equity \\
\hline $\mathrm{CgbO}$ & Cash generated by operations \\
\hline CMAD & Coefficient of median absolute deviation \\
\hline $\mathrm{CV}$ & Coefficient of variation \\
\hline $\mathrm{d}$ & Debt \\
\hline DCF & Discounted cash flow \\
\hline$\varepsilon$ & Error term \\
\hline EBIT & Earnings before interest and tax \\
\hline EBITDA & Earnings before interest, tax, depreciation and amortisation \\
\hline FCFF & Free cash flow to the firm \\
\hline GP & Gross profit \\
\hline$i$ & Entity $i$ \\
\hline IC & Invested capital \\
\hline IMP & Potential percentage improvement \\
\hline IPR & Inter-percentile range \\
\hline IQR & Inter-quartile range \\
\hline JSE & JSE Securities Exchange \\
\hline MAD & Median absolute deviation \\
\hline $\operatorname{Max}$ & Maximum \\
\hline MCap & Market capitalisation \\
\hline Min & Minimum \\
\hline MVIC & Market value of invested capital \\
\hline $\mathrm{N}$ & Number of observations \\
\hline NCIfIA & Net cash inflow from investing activities \\
\hline NCIfOA & Net cash inflow from operating activities \\
\hline $\mathrm{P}$ & Market price \\
\hline $\mathrm{PwC}$ & PricewaterhouseCoopers \\
\hline $\mathrm{R}$ & Revenue \\
\hline SD & Standard deviation \\
\hline$t$ & Time period $t$ \\
\hline TA & Total assets \\
\hline USA & United States of America \\
\hline WACC & Weighted average cost of capital \\
\hline$\alpha_{i t}$ & Actual value driver \\
\hline$\lambda_{t}^{e}$ & Actual equity-based multiple \\
\hline$\hat{\lambda}_{t}^{e}$ & Estimated equity-based peer group multiple at time period $t$ \\
\hline$\hat{\lambda}_{t}^{n}$ & Estimated entity-based peer group multiple at time period $t$ \\
\hline$V_{i t}^{e}$ & Actual equity value of company $i$ at time period $t$ \\
\hline$\hat{V}_{i t}^{e}$ & Estimated equity value of company $i$ at time period $t$ \\
\hline
\end{tabular}




\section{APPENDIX B: CLASSIFICATION OF VARIABLES}

The classification of the variables was primarily derived from the descriptions as presented in the McGregor BFA user manuals.

\section{Market Price Variable}

1. MCap represents the market value of a company's issued ordinary share capital. MCap is calculated by multiplying the market price per share as at the company's financial year end with the issued volume of shares at the same date.

2. MVIC represents the value of the entity as a whole. MVIC is calculated as MCap plus preference share capital plus interest-bearing debt.

\section{Earnings-based Multiples}

3. GP represents and is calculated as the difference between sales or revenue and the cost of sales.

4. EBITDA represents a company's earnings before interest paid, taxation, depreciation and amortisation. It is calculated by taking GP, adding other income (excluding income from associates) and deducting all expenses, but adding back interest paid, taxation, depreciation and amortisation.

5. EBIT represents a company's earnings before interest paid and taxation. It is calculated by taking EBITDA and deducting depreciation and amortisation.

\section{Book Value-based Multiples}

6. TA represents the total of all the assets employed by the company. It is calculated by adding total fixed assets, total long-term investments and total current assets.

7. IC represents the total cash investment by fund providers. It is calculated by deducting cash and cash equivalents from TA.

\section{Revenue-based Multiple}

8. Revenue represents the gross sales of the company.

\section{Cash Flow-based Multiples}

9. CgbO represents pre-tax cash flows net of working capital expenditure, as per the cash flow statement.

10. NCIfOA represents post-tax operational cash flows. It is calculated by taking $\mathrm{CgbO}$ and deducting net interest, net dividends and income taxation.

11. NCIfIA represents post-tax operational cash flows net of fixed capital expenditure. It is calculated by taking NCIfOA and deducting acquisitions of fixed capital items net of capital gains tax.

12. FCFF represents post-tax cash flows that are available to be distributed to all the fund providers of a company, net of capital expenditure to grow or maintain the business. It is calculated by taking NCIfIA and adding back non-operational items, such as net interest and net dividends. 


\section{NOTES}

